\title{
Understanding the association between mean arterial pressure and mortality in young adults
}

\author{
Yue Fei
}

Mean arterial pressure (MAP), the average blood pressure (BP) over a cardiac cycle, is an important measurement of the overall circulating pressure load. Adequate MAP (at least $60 \mathrm{~mm} \mathrm{Hg}$ ) is needed to sustain sufficient perfusion pressure for tissue perfusion so as to reduce hypoperfusion and organ failure, furthermore, prevent death. ${ }^{1}$ MAP is highly associated with systolic BP (SBP) and diastolic BP (DBP). Previous studies have confirmed MAP as an important independent predictor of metabolic syndrome, cardiovascular disease (CVD) and cardiovascular death. ${ }^{2-7}$ However, unlike the well-established strong association between MAP and cardiovascular mortality, ${ }^{4-6}$ the evidence on the predictive utility of MAP in the risk of allcause death remains controversial. MAP was found to be comparable to SBP in predicting the risk of CVD mortality and all-cause mortality across all age and gender groups in the Chicago Heart Association cohorts, ${ }^{6}$ while every $10 \mathrm{~mm} \mathrm{Hg}$ increase in MAP was reported to be independently associated with a $14 \%$ increase in the risk of allcause mortality in the elderly with isolated systolic hypertension in the USA. ${ }^{7}$ However, in Middle Eastern populations without baseline CVD and antihypertensive medications, MAP showed insignificant relation with all-cause mortality among the elderly, although it was strongly associated with an increased risk of CVD mortality and all-cause mortality in those aged $<60$ years. $^{5}$ This evidence based on the middle-aged or elderly populations is inadequate to define the role of MAP in predicting allcause death among the young, who are generally 'healthy'.

Sun et $a l^{8}$ evaluated the associations between MAP and all-cause mortality in adults aged between 18 and 40 years, filling a gap in our understanding of the relationship between MAP and all-cause death in the general population. The authors analysed data from the US National

Correspondence to Dr Yue Fei, Medicine, University of Hong Kong, Hong Kong, Hong Kong; fayeyf@con nect.hku.hk
Health and Nutrition Examination Survey (1999-2006) and concluded that there was no significant association between MAP and all-cause mortality in a young adult population. Unlike previous studies, this 'healthy' population has no history of CVD, low rates of smoking and obesity, and relatively normal SBP levels. Therefore, this study with relatively short follow-up may lack the power to address all-cause mortality. The findings do not come as a surprise.

Moreover, as MAP was estimated indirectly rather than directly measured, the calculation methods may affect the results. In this paper, the authors used the standard calculation for MAP (DBP plus one-third of pulse pressure (PP)) regardless of heart rate (HR), which could introduce errors and be less accurate than the new formula, namely, $\mathrm{MAP}=\mathrm{DBP}+[(0.33$

$+(\mathrm{HR} \times 0.0012)] \times(\mathrm{PP}) .{ }^{1}$ This limitation also makes the use of MAP as a risk predictor inferior to SBP in clinical practice. Current guidelines for hypertension diagnosis and management neither define an optimal MAP as a target nor use MAP in risk calculations. SBP remains the main parameter representing the risk of CVD posed by high BP. $^{9}{ }^{10}$ Using MAP in combination with SBP does not improve prognostication. ${ }^{3}$ In this regard, whether MAP can be used as an independent predictor of all-cause mortality remains to be answered by more research, especially in the young.

MAP increases with age as a result of arterial stiffening. The findings of Sun et al, on the other hand, reflect the importance of lifestyle management in BP lowering from an early age. ${ }^{2} 11$ The lowered threshold of the definition of hypertension in the 2017 American College of Cardiology/American Heart Association guideline on the prevention, detection, evaluation and management of high $\mathrm{BP}^{9}$ substantially increases the prevalence of hypertension in the general population, particularly in the young. However, BPcontrol in this population group is often neglected because of the low rates of CVD and death. In the study by Sun et al, there were very few deaths from CVD or non-
CVDs such as sepsis in the 'healthy' young adult participants, which limited the assessment of the association between MAP and death. The regulation of MAP is through a complex interaction between the cardiovascular, renal and autonomic nervous systems. Although the impact of MAP on all-cause mortality in young adults has not been demonstrated, it still seems prudent to maintain MAP within the normal range $(70-100 \mathrm{~mm} \mathrm{Hg})$ at all ages. Nevertheless, this study is valuable in revealing the association between MAP and all-cause death in the young, thus prompting more studies on MAP and more studies focusing on early BP control.

Contributors YF prepared this manuscript and had final responsibility for the decision to submit for publication.

Funding The authors have not declared a specific grant for this research from any funding agency in the public, commercial or not-for-profit sectors.

Competing interests None declared.

Patient consent for publication Not required.

Provenance and peer review Commissioned; externally peer reviewed.

(C) Author(s) (or their employer(s)) 2020. No commercial re-use. See rights and permissions. Published by BMJ.

(A) Check for updates

To cite Fei Y. Postgrad Med J 2020;96:453-454.

Received 31 March 2020

Revised 21 April 2020

Accepted 24 April 2020

Postgrad Med J 2020;96:453-454.

doi:10.1136/postgradmedj-2020-137751

ORCID iD

Yue Fei http://orcid.org/0000-0002-4622-6377

\section{REFERENCES}

1 Razminia M, Trivedi A, Molnar J, et al. Validation of a new formula for mean arterial pressure calculation: the new formula is superior to the standard formula. Catheter Cardiovasc Interv 2004;63:419-25

2 Cheung BMY, Wat NMS, Man YB, et al. Relationship between the metabolic syndrome and the development of hypertension in the Hong Kong cardiovascular risk factor prevalence Study-2 (CRISPS2). Am J Hypertens 2008;21:17-22.

3 Sesso HD, Stampfer MJ, Rosner B, et al. Systolic and diastolic blood pressure, pulse pressure, and mean arterial pressure as predictors of cardiovascular disease risk in men. Hypertension 2000;36:801-7.

4 Mosley WJ, Greenland P, Garside DB, et al. Predictive utility of pulse pressure and other blood pressure measures for cardiovascular outcomes. Hypertension 2007;49:1256-64.

5 Hadaegh F, Shafiee G, Hatami M, et al. Systolic and diastolic blood pressure, mean arterial pressure and pulse pressure for prediction of cardiovascular events and mortality in a middle Eastern population. Blood Press 2012:21:12-18. 
6 Miura K, Dyer AR, Greenland P, et al. Pulse pressure compared with other blood pressure indexes in the prediction of 25-year cardiovascular and all-cause mortality rates: the Chicago heart association detection project in industry study. Hypertension 2001;38:232-7.

7 Domanski MJ, Davis BR, Pfeffer MA, et al. Isolated systolic hypertension: prognostic information provided by pulse pressure. Hypertension 1999;34:375-80.
8 Sun S, Lo K, Liu L. Association of mean arterial pressure with all-cause and cardiovascular mortality in young adults. Postgrad Med J 2020: postgradmedj-2019137354.

9 Whelton PK, Carey RM, Aronow WS, et al. 2017 ACC/ AHA/AAPA/ABC/ACPM/AGS/APhA/ASH/ASPC/NMA/

PCNA guideline for the prevention, detection, evaluation, and management of high blood pressure in adults: Executive summary: a report of the American College of
Cardiology/American heart association Task force on clinical practice guidelines. Hypertension 2018;71:1269-324.

10 Fei Y, Tsoi M-F, Cheung BMY. Determining the optimal systolic blood pressure for hypertensive patients: a network meta-analysis. Can J Cardiol 2018;34:1581-9.

11 Cheung BMY, Or B, Fei Y, et al. A 2020 vision of hypertension. Korean Circ J 2020;50:e70. 